\author{
М.В. ПАНЬШИНА ${ }^{1}$, К.А. ХАДАРЦЕВА ${ }^{1}$, Р.В. КУПЕЕВ ${ }^{2}$ \\ ${ }^{1}$ Тульский государственный университет, медицинский институт, Тула \\ ${ }^{2} \mathrm{OOO}$ «Аирмед», Москва
}

\begin{abstract}
Исследование посвящено определению возможности профилактики психоэмоционального стресса при дисменорее у женщин фертильного возраста воздействием транскраниальной электростимуляции в сочетании с лазерофорезом серотонина. Наблюдалось 57 женщин с дисменореей. Сформированы: основная группа из 34 пачиенток, получавших, на фоне базовой терапии, транскраниальную электростимуляцию и лазерофорез серотонина, и контрольная группа из 23 женшин. Проведена оченка психологического статуса до и после лечения. Показана возможность коррекции симптоматики психоэмоционального стресса, вызванного эндогенными причинами (патологией желудочно-кищечного тракта).
\end{abstract}

Ключевые слова: дисменорея, психоэмочиональный стресс, лазерофорез, серотонин, транскраниальная электростимулячия, механизмы адаптации.

Введение. Управление механизмами адаптация при психоэмоциональном стрессе (ПЭС) осуществляется на уровне микроциркуляции, где формируются механизмы адаптации - кататоксические программы адаптации (КПА) и синтоксические программы адаптации (СПА), определены продукты метаболизма, участвующие в формировании программ адаптации, в частности, фертильные факторы $[1,2,4]$.

Ограничивает стрессовую реакцию и предупреждает стрессорные повреждения при действии повреждающих факторов внешней и внутренней среды - ГАМК-ергическая система через фертильные факторы гипоталамо-гипофизарно-репродуктивной системы. При этом активируются СПА, проявляющиеся активацией холинергических, антиоксидантных и противосвертывающих механизмов крови и явлениями иммунносупрессии $[5,11,12]$.

ПЭС может провоцироваться заболеваниями женских половых органов, при которых развиваются вторичные соматогенные депрессии, уменьшающиеся при купировании основных симптомов заболевания. Сдерживание и торможение эмоций являются фактором риска для здоровья в целом, а хронические формы сдерживания - стрессором, воздействующим на иммунную и другие системы организма $[9,13]$.

Лечение ПЭС осуществляется медикаментозными и немедикаментозными способами. Для оптимизации действия лекарственных препаратов и биологически активных растительных веществ использует- ся способ локального транскутанного (чрескожного) проведения лекарственных препаратов. Применяются технологии транскутанного проведения лекарственных препаратов, например, лазерофореза, как способа проведения сложных биологически активных веществ во внутренние среды организма при помощи лазерного излучения низкой интенсивности через активацию трансмембранного механизма переноса биологически значимых веществ [7]. Серотонин участвует в процессах регуляции жизнедеятельности через ГАМК-допаминергическую систему. При этом значимы процессы, происходящие в этой системе через общеизвестные эффекты опиоидных пептидов, высвобождение которых происходит при транскраниальной электростимуляции (ТЭС) $[3,6,8,10]$.

Цель исследования - определить возможность предупреждения развития эндогенного психоэмоционального стресса у женщин с дисменореей воздействием ТЭС в сочетании с лазерофорезом серотонина.

Материалы и методы исследования. Наблюдалось 57 женщин фертильного возраста с дисменореей. Сформированы: основная группа из 34 пациенток, получавших, на фоне базовой терапии, транскраниальную электростимуляцию и лазерофорез серотонина, и контрольная группа из 23 женщин, получавших только базовую терапию. 


\begin{tabular}{|c|c|c|c|}
\hline \multicolumn{4}{|c|}{ 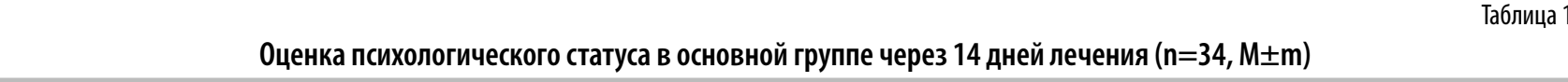 } \\
\hline Показатели & $\begin{array}{c}\text { До лазерофореза } \\
\text { серотонина и ТЭС+базовое } \\
\text { лечение }\end{array}$ & $\begin{array}{c}\text { После лазерофореза } \\
\text { серотонина и ТЭС+базовое } \\
\text { лечение }\end{array}$ & $\mathrm{p}$ \\
\hline Индекс Хильдебрандта & $5,22 \pm 0,91$ & $7,89 \pm 1,32$ & $<0,05$ \\
\hline Личностная тревожность в баллах & $32,13 \pm 0,74$ & $21,65 \pm 0,57$ & $<0,05$ \\
\hline Реактивная тревожность в баллах & $31,24 \pm 0,44$ & $23,21 \pm 0,65$ & $<0,05$ \\
\hline Индекс САН в баллах & $4,28 \pm 0,07$ & $5,68 \pm 0,04$ & $<0,05$ \\
\hline HADS-A в баллах & $8,51 \pm 1,34$ & $5,32 \pm 0,11$ & $<0,05$ \\
\hline HADS-B в баллах & $6,03 \pm 0,12$ & $3,45 \pm 0,02$ & $<0,05$ \\
\hline \multicolumn{4}{|c|}{ Оценка психологического статуса в контрольной группе через 14 дней базового лечения ( $\mathrm{n}=23, \mathrm{M} \pm \mathrm{m}$ ) } \\
\hline Показатели & До базового лечения & После базового лечения & $\mathrm{p}$ \\
\hline Индекс Хильдебрандта & $5,24 \pm 0,65$ & $5,48 \pm 3,64$ & $>0,05$ \\
\hline Личностная тревожность в баллах & $31,23 \pm 0,59$ & $30,74 \pm 0,66$ & $>0,05$ \\
\hline Реактивная тревожность в баллах & $29,31 \pm 0,64$ & $28,23 \pm 0,76$ & $>0,05$ \\
\hline Индекс САН в баллах & $4,51 \pm 0,35$ & $4,47 \pm 0,26$ & $>0,05$ \\
\hline HADS-A в баллах & $8,76 \pm 2,15$ & $8,37 \pm 0,22$ & $>0,05$ \\
\hline HADS-B в баллах & $5,77 \pm 0,22$ & $5,46 \pm 0,12$ & $>0,05$ \\
\hline
\end{tabular}

Осуществлена оценка психологического статуса до и после лечения. Лазерофорез серотонина проводился с помощью устройства «Матрикс» по известной методике [11]. Применялся раствор серотонина для внутривенного и внутримышечного введения по 10 мг в ампуле. Воздействие на деятельность ГАМК-допаминергической системы осуществляли методом ТЭС при наложении электродов портативного устройства «Альфария» на ушные раковины по апробированной методике [7].

Оценка психологического статуса до и после коррекции проявлений психоэмоционального стресса осуществлялось по Госпитальной Шкале Тревоги и Депрессии (HADS), определяли $H A D S-A$ (от англ. Anxiety - тревога) и HADS-B (от англ. Depression депрессия), по опроснику САН (самочувствие, активность, настроение), по индексу межсистемной согласованности сердечнососудистой и респираторной систем (индексу Хильдебрандта). Тестирование по методике Спилбергера-Ханина проводилось с применением двух бланков: один бланк для измерения показателей ситуативной тревожности, а второй - для измерения уровня личностной тревожности.

Результаты и их обсуждение. Субъективные ощущения обследуемых основной группы заключались в уменьшении интенсивности болевого синдрома, связанного с основным заболеванием, улучшении сна, появлении мотивации к выздоровлению - уже после двух недель лечения. В контрольной груп- пе (только на базовой терапии) время достижения субъективного и объективного улучшения было более поздним, что отразилось на оценке психологического статуса до и после лечения (табл. 1, 2).

Таким образом, двухнедельный курс лечения в случае сочетания базовой терапии с ТЭС и лазерофорезом серотонина у женщин с дисменореей в основной группе - обеспечивает более быструю стабилизацию психологического статуса, чем в контрольной группе. Это объяснимо с позиции значимости многокомпонентного участия программ адаптации в управлении гомеостазом. При этом особую значимость приобретает воздействие на ГАМК-допаминергическую систему через серотониновые и опиоидергические механизмы.

Заключение. Транскраниальная электростимуляция в сочетании с лазерофорезом серотонина является значимым дополнением базисной терапии дисменореи, что обеспечивает коррекцию симптоматики психоэмоционального стресса, вызванного эндогенными причинами (нарушениями менструального цикла).

\section{ЛИТЕРАТУРА:}

1. Гусак Ю.К., Дармограй В.Н., Карасева Ю.В., Морозов В.Н., Морозова В.И., Хадарцев А.А., Хапкина А.В., Чуксеева Ю.В. Стимулирования синтоксических и кататоксических программ адаптации при действии на гипоталамус естественных синтоксинов и кататоксинов // Вестник новых медицинских технологий. 2002. № 1. С. 56-60. 
2. Дармограй В.Н., Карасева Ю.В., Морозов В.Н., Морозова В.И., Наумова Э.М., Хадарцев А.А. Фитоэкдистероиды и фертильные факторы как активаторы синтоксических программ адаптации // Вестник новых медицинских технологий. 2005. № 2. С. 82-84.

3. Живогляд Р.Н., Беляева Е.А., Хадарцева К.А., Паньшина М.В. Сочетание транскраниальной электростимуляции и гирудотерапии в комплексе реабилитационно-восстановительных мероприятиях при хроническом болевом синдроме // В сборнике: Диверсификация реабилитационно-восстановительных технологий к 25-летию вузовского медицинского образования и науки Тульской области (сборник научных статей). Тула, 2017. С. 51-57.

4. Зилов В.Г., Хадарцев А.А., Еськов В.М., Винокуров Б.Л., Морозов В.Н., Кидалов В.Н., Филато-ва О.Е., Гонтарев С.Н., Хадарцева К.А., Цогоев А.С., Наумова Э.М., Крюкова С.В., Митрофанов И.В., Валентинов Б.Г., Седова О.А. Восстановительная медицина: Монография / Под ред. А.А. Хадарцева, С.Н. Гонтарева, В.М. Еськова. Тула: Изд-во ТулГУ - Белгород: ЗАО «Белгородская областная типогра-фия», 2010. Т. І. 298 с.

5. Карасева Ю.В., Гусак Ю.К., Хадарцева К.А., Паньшина М.В. Антисвертывающие и антиокис-лительные системы в механизмах адаптации у женщин // В сборнике: ПЕРСПЕКТИВЫ ВУЗОВСКОЙ НАУКИ к 25-ЛеТИю вузовского медицинского образования и науки Тульской области (сборник трудов). Тула, 2016. С. 23-39.

6. Купеев В.Г., Паньшина М.В., Хадарцева К.А., Фудин Н.А. Сочетание транскраниальной элек-тростимуляции с лазерофорезом мексидола и гиалуроната в тренировочном процессе спортсменок-тяжелоатлеток с дисменореей // В сборнике: Диверсификация реабилитационно-восстановительных тех-нологий к 25-летию вузовского медицинского образования и науки Тульской области (сборник научных статей). Тула, 2017. С. 14-22.

7. Купеев В.Г., Хадарцев А.А., Троицкая Е.А. Технология фитолазерофореза. Тула: Изд-во «Тульский полиграфист», 2001. 120 c.
8. Наумова Э.М., Хадарцева К.А., Беляева Е.А., Паньшина М.В. Критерии сочетанного применения медикаментозных и не медикаментозных методов лечения в клинической практике Тульской и Сургутской научных школ (обзор литературы) // Вестник новых медицинских технологий. Электронное издание. 2016. № 2. Публикация 8-5. URL: http://www.medtsu.tula. ru/VNMT/Bulletin/E2016-2/8-5.pdf (дата обращения: 10.06.2016). DOI: $10.12737 / 20082$.

9. Паньшина М.В., Силаева Е.Б., Раннева Л.К. Возможности диагностики и совместного применения немедикаментозных способов профилактики и реабилитации преэклампсии (научный обзор литературы) // Вестник новых медицинских технологий. 2013. № 1. Публикация 2-139. URL: http://medtsu.tula.ru/VNMT/Bulletin/E20131/4557.pdf (Дата обращения: 15.10.2013).

10. Хадарцев А.А., Морозов В.Н., Карасева Ю.В., Хадарцева К.А., Гордеева А.Ю. Психонейроим-мунологические программы адаптации, как модели дизадаптации у женщин с нарушенным репродуктивным циклом // Фундаментальные исследования. 2012. № 5 (часть 2). C. $359-365$.

11. Хадарцев А.А., Морозов В.Н., Карасева Ю.В., Хадарцева К.А., Фудин Н.А. Патофизиология стресса, как баланс стрессогенных и антистрессовых механизмов // Вестник неврологии, психиатрии и нейрохирургии. 2012. № 7. С. 16-21.

12. Хадарцев А.А., Морозов В.Н., Хрупачев А.Г., Карасева Ю.В., Морозова В.И. Депрессия антистрессовых механизмов как основа развития патологического процесса // Фундаментальные исследования. 2012. № 4 (часть 2). С. 371-375.

13. Хадарцев А.А., Фудин Н.А. Психоэмоциональный стресс в спорте. Физиологические основы и возможности коррекции (обзор литературы) // Вестник новых медицинских технологий. Электронное издание. 2015. № 3. Публикация 8-4. URL: http://www.medtsu.tula.ru/ VNMT/ Bulletin/E2015-3/5256.pdf (дата обращения: 30.09.2015). DOI: $10.12737 / 13378$

\title{
TRANSCRANIAL ELECTROSTIMULATION AND SEROTONIN LASER PHORESIS IN PSYCHO-EMOTIONAL STRESS IN WOMEN WITH DYSMENORRHEA
}

\author{
M.V. PAN'SHINA, K.A. KHADARTSEVA, R.V. KUPEEV
}

The study is devoted to determining the possibility of preventing psycho-emotional stress in dysmenorrhea in women of fertile age by the action of transcranial electrostimulation in combination with serotonin laser phoresis. There were 57 women with dysmenorrhea. The main group of 34 patients who were treated by baseline transcranial electrostimulation and serotonin laser phoresis; the control group consisted of 23 women. Before and after treatment the psychological status was assessed. The possibility of correcting the symptoms of psycho-emotional stress caused by endogenous causes (pathology of the gastrointestinal tract) is shown.

Keywords: dysmenorrhea, psycho-emotional stress, laser phoresis, serotonin, transcranial electrostimulation, adaptation mechanisms. 